\title{
The research of probability theory and mathematical statistics education based on the CDIO teaching method
}

\author{
Shulan $\mathrm{ma}^{1}$ \\ ${ }^{1}$ School of Mathematics and Computer Science, NingXia Normal University, Guyuan, NingXia, China
}

Keywords:CDIO, Probability Theory and Mathematical Statistics, Teaching and Research

\begin{abstract}
From the summary of university mathematics education is facing problems and difficulties, combined with the characteristics of probability and mathematical statistics course and the present situation of several aspects of teaching, using the CDIO project teaching, cultivating students' conception, design, implementation and operation of engineering practical ability and team cooperation ability. Discussion and research reform problems in the teaching of probability and mathematical statistics course, puts forward some new Suggestions to improve the quality of teaching effectively.
\end{abstract}

\section{Introduction}

Probability and mathematical statistics is the study of random phenomena statistical regularity, institutions of higher learning are all kinds of engineering, science, management science and economics and so on the specialized basic courses, is the student study follow-up after the higher mathematics course, learning this course requires calculus as a foundation [1]. Probability and mathematical statistics research objects with randomness and uncertainty, and it and real life are closely linked, with its theory and method has been widely used in natural science, social science, engineering, construction, military science, biological engineering, and many areas of the economy, such as economic management, financial engineering, insurance actuarial, economic forecasting, etc [1]. In recent years, from the college entrance examination to graduate entrance examination has increasing trend of curriculum content of probability and statistics. Therefore, in order to achieve the teaching goal of this discipline, lay the foundation for the students learning practice, do a good job in the teaching of this course is important.

CDIO engineering education mode is the latest achievements of engineering education reform in recent years, in 2000 by the Massachusetts institute of technology, the Swedish royal institute of technology, Sweden, moss industrial university founded jointly with Linkoping university in Sweden, where $\mathrm{C}$ on behalf of the design (conceive), $\mathrm{D}$ (desigll) on behalf of the design, I represents the implementation (implement), $\mathrm{O}$ on behalf of the operation (operate) [1]. The core values of the model by using in the teaching process of "design a design, the implementation of" operation to make the students experience the product (system) from production of finished product whole life cycle, improve the students' innovation ability and engineering practice ability, at the same time "encourage students to active learning and comprehensive study, promote students to learn the product production process and system building skills, learning and communication and cooperation skills".

\section{The present situation of the probability theory and mathematical statistics course in colleges and universities}

Today's theory of probability and mathematical statistics teaching in many ways, constrained by the traditional way, with the rapid development of science and technology of today seem to be some single, rigid, also conflicts with the characteristics of college students' innovation, achieves, problems mainly focused on the content of the teaching material and teaching methods [2]. With traditional and sealing ability in the teaching material of, there is no well penetration concept of modern mathematics, theoretical and ignore the application of theory and practical. Teaching material too much consider the integrity of the integrity of the content and argument, the lack of background and application of the outstanding problems, don't pay attention to combining with the actual, cause unnecessary stress 
to the student; Problem sets of establishment are basically artificial formula of simple applications rather than from the actual life, can't fully induce students' creative thinking ability.

Teach type teaching mode, although to a certain extent, make the students master the basic knowledge, improve the calculation ability, logical reasoning ability, application ability, but also exist some problems [2]. This acceptance learning model without students to explore, to seek, to find, less to ask students to use their own thinking to overcome obstacles. On the contrary, only is to understand, memory, consolidate and reappearance, ignored the teaching is a process of interaction between teaching and learning, there is no good to mobilize students' learning initiative, not based on cultivating students' learning ability and the different students' individual character development, only pay attention to the accumulation of knowledge, students ignore the development of the students application ability [1]. This is both comfortable and tedious learning and the characteristics of college students active and lively, be good at thinking in images, hinder the development of students' thinking and ability, to stimulate students' interest in learning, innovation is not likely to let a person, will only produce be disgusted or studying for the exam.

So this kind of traditional teaching lack of vitality and popularity, it is difficult to keep pace with The Times. Therefore, we must constantly from the reality complement each other, in the teaching of probability theory and mathematical statistics truly "teaching and learning, with" together, to meet the needs of The Times and social development.

\section{CDIO engineering education mode}

To make the practice teaching to cultivate student's professional accomplishment and an effective means of practical operation skills, we must improve the traditional teaching mode and method. Strengthen the cultivation of independent operation skills, comprehensively improve the quality of practice teaching. As a result, proposed "the need is real, hands-on is true, knowledge is a bridge, ability is the source of the teaching idea, with ability as the standard, in order to develop technology application ability as the main line, the students' knowledge, skills, ability, quality of training into an organic whole, using effective teaching methods, strengthen the combination of industry and school, actively and steadily promote the reform of curriculum, improve teaching quality.

CDIO cultivating the ability of engineering graduates can be divided into engineering foundation knowledge, personal ability, interpersonal ability to team and engineering level, four requirements in the cultivation of the comprehensive way so that the students in these four aspects to the expected goal [2]. Thus, in the process of construction of probability theory and mathematical statistics teaching, highlight the course system of systematic and integrity, building multi-level practical teaching content, experiment courses should be don't ask, don't break, difficulty gradually increase, the essential content. Hierarchical and series makes the practice training, in order to system to strengthen the students' practical ability. Handle the relations between the subject and related courses, so as to ensure the completeness and systematisms of curriculum system.

\section{The application of CDIO education model in probability theory and mathematical statistics course}

To cultivate students' innovative experiment ability as the core, build a set of complete new CDIO innovative experimental teaching mode, clear course overall goal of practice teaching. Insist on skills needs as the guidance, based on the requirement of the job qualification standard principles. Based on the principle of guidance, autonomy, openness, determine the practice teaching take the student as the main body, strengthen the ability of autonomous learning, analysis and problem solving skills. Based on the principle of practicality, creativity, emphasis on the cultivation of ability and quality, less practice think much, speak more so that the students in practice correctly [3]. Pay attention to exert students' creativity, analysis, independent thinking from different angles to inspire students' innovative consciousness.

Interest stimulate. Interest is the best teacher, but also an important factor of students to learn a course. In the teaching process teachers should actively take all kinds of appropriate methods, can 
inspire learning enthusiasm, arouse the students' learning motivation, and guide students to become masters of learning. So if grasp each concept trigger interest in the opportunity, so students' learning effect will be different. Mathematics is a very abstract subject, especially the theory of probability and mathematical statistics concept, theorem, formula, theorem, formula derivation of the complex. In teaching process if the teacher just read about the concept, theorem, formula, theorem is just for some logical deduction, so students are difficult to concentrate for a long time, never seemed interested in knowledge also, it is not easy to achieve the desired learning effect. Therefore, when teaching teachers should pay attention to use the humorous teaching language first, give students a relaxed feeling. Second, since this subject research theory penetrates into every aspect of daily life, each theory has its practical background [3]. Therefore, in the teaching, starting from the actual background of concept, selecting proper living example, and introduces some basic concepts, the theorem of related background knowledge, causes student's study interest, to attract the attention of students, make students experience in a relaxed, pleasant environment each basic concept, theorem and formula of producing process, to master the discipline of thought and the method to solve the problem.

CDIO case teaching. Probability and mathematical statistics is a branch in solving practical problems in the process of developing discipline, the ideas of the theory of probability and mathematical statistics method, the principle, the formula from the close to life problems and case introduction, most can stimulate students' interest. Case teaching method is to put the case as a teaching tool, to conduct the students to the practical problems, through analysis and discuss with each other, to mobilize students' initiative and enthusiasm, and put forward the basic ways and means to solve the problem of a kind of CDIO teaching method [4]. Teachers in the teaching process from the intuitive background of each concept and carefully selected some closely related with our life and interesting as an example, through case teaching combine learning theoretical knowledge and practical life, the abstract mathematics with vivid and interesting case, mobilize students' initiative and enthusiasm, cultivate students' ability to analyze and solve problems. Case should be appropriately extended textbook content, to learn the background and hot issues of society, economy, life, especially in combination with the professional background of the students. For example engineering specialty should choose more cases associated with the computer, communications, machinery and so on, while economic management class try to choose business, insurance related cases. To stimulate students' interest. To mobilize their enthusiasm and initiative of learning.

The traditional teaching mode of teaching is often straightforward to definitions and theorems such as accurate expression to present in front of students, and these processed refined language tend to erase the original thought. Case teaching is trying to make up for the shortcomings, reappearance original thought. This would solve a key problem, how to use case. Original ideas are generally the spark of inspiration to come from somewhere, or some kind of Epiphany [4]. Case, in fact, have the effect, lets the student participate in the case analysis, put forward his own ideas, induction and inspired by the teacher and other students, often the essence of problems surfaced, the teachers need to do is to summarize and extract the flash of thought. For example, in the content of the teaching of interval estimation and hypothesis test, guides the student to discuss the differences and relations between the two parts, through the discussion, make the student to this part of content, the principle of a new understanding, and provide the flexibility to master the knowledge. We combined with the characteristics of probability theory and mathematical statistics applied strong, in the classroom Teaching, CDIO also pays attention to collect the instance in economic life, and select the appropriate in accordance with the contents of each chapter serve teaching cases. Probability theory, for example, the content of study, students can't understand very well the principle of full probability formula and bays formula.

Discussion-based CDIO teaching. Discussion teaching method refers to the students under the guidance of the teacher, around a certain problem or some specific aspects of the social phenomenon, is an unit with group or class, the teacher and students, between students and students to carry out the positive discussion, debate and even argued, views, questioned each other, inspire each other, in order to understand and solve problems of a kind of CDIO teaching method. In probability tutorial, for 
example, can put forward the question: if you are in for a game activities, host, pointing to have Numbers for a, b, c three door, only a door has a car, if guess can drive away [5]. If you guessed a gate have a car, and then the host will b, c car free open the gate, such as gate c car free. Now choose $b$ gate asked whether you want to change?

Discusses the teachers can guide students to carry out the answer to this problem, should be changed, but a lot of people always think impassability, think that change does not change, the probability is $1 / 3$. In fact, a number one third door is the probability. Then, in $b$ and c $2 / 3$ of door is the probability that a car;since c \# without a car door is opened, the b door is the probability that a car two-thirds, so should change [5]. Is this writer Margaret spellings avant1991 years published in the American journal of review questions caused from all walks of life to, a professor at the university, even as America is in the gulf war of operational staff are the topic of discussion. Through questioning, developing students' thinking, so that the students positive thinking, and motivate all students to actively participate in, so that to improve the students' learning enthusiasm and change the habits of the students' passive learning, enhance the consciousness of the students' active participation in classroom teaching, but also arouse the enthusiasm of the students' learning, and through multilateral exchanges between teachers and students, live, each other to explore, to seek to acquire knowledge and improve students' quality in an all-round way.

The CDIO experimental teaching. Many students finish the study of probability theory and mathematical statistics, in the professional courses, in the face of large amounts of data, need to tend to be a hindrance when applying the idea of statistical methods to analyze the phenomena, the cause of this phenomenon has two aspects [6]:

1) The lack of flexibility and ability to apply knowledge to solve practical problems.

2) The large amount of data, calculation is too complex, difficult to achieve by hand.

For the first case we through case combining teaching content and students major to improve the students' ability to use. Open a computer LABS in the second case, let the students master the relevant computer software for statistical analysis, training students applied mathematics software to solve the problem. In the teaching of probability theory and mathematical statistics commonly used Matlab, SPSS, SAS, Excel and other mathematical software to solve practical problems, through the "problem - experiment validation - communication - guess - innovation" mode, causes the student to deepen teaching to a deeper understanding of knowledge, but also enhances the ability of independent thinking and solving practical problems. Matlab statistic tool box contains almost such as parameter estimation, hypothesis testing, analysis of variance, regression analysis, etc. All areas of mathematical statistics [6]. Probability and statistics course probability calculation, data processing, parameter estimation, hypothesis testing and interval estimation complex calculations are auxiliary teaching software can be used.

The Matlab software and integrate the theory of probability and mathematical statistics teaching, can make the teaching method is improved, improve teaching efficiency and teaching level, promote the reform of the teaching of probability and mathematical statistics and the development of curriculum construction. Mathematical experiments, and the practice, the combination of theory teaching and student abstract theory for concrete, can make the students from passive to accept into active participation, arouse the students' interest in learning this course, and cultivate students' creative spirit and creative ability. Excel software chosen as the experiment platform, a class for students in the process of some subjects, such as,

1) Random experiment simulation of a coin;

2) Normal distribution simulation;

3) The point estimation of parameters

4) The interval estimation;

5) The hypothesis test.

Each experiment, the teacher give to experiment topic background, the purpose of the experiment and requirements and main contents of the experiment. This not only improve the students' interest in learning, but also strengthened the student to utilize the theory of probability and mathematical statistics principle solution actual problem ability. 
CDIO Theory teaching. Teaching content and curriculum system is the basis of theory teaching, it determines the student's knowledge and ability structure, determines the quality of conveying talents to the society [2]. Therefore, adhering to the idea of running schools, in the course system design adhere to the thinking of thick foundation, wide caliber, relying on superior resources in our school, in the professional course system design fully embody the characteristics of the school, and focus on analyzing the change of the social demand and student situation, timely adjust the course system, optimize course structure, updating the teaching contents, strengthen the logical cohesion between courses. Through years of efforts, the school construction with their characteristics of reasonable theory curriculum system, which based on the individual courses, forming course group, again through the course of theory of cultivating the ability of corresponding to the requirements.

\section{Summary}

Probability and mathematical statistics the purpose of education is to develop a solid technical foundation, wide professional knowledge, comprehensive engineering systems engineer skills and good team cooperation ability. In this paper CDIO education concept of probability theory and mathematical statistics to try to engineering education reform, and discussed the concrete analysis. Change the past theory of light practice, emphasis on individual ability and ignore the team cooperation, attaches great importance to the professional knowledge and neglecting the cultivation of innovative ability education mode, it is the current domestic engineering undergraduate education reform direction.

\section{Acknowledgement}

Undergraduate teaching quality and teaching reform project of 2017 Ningxia institutions of higher learning - Important professional (group) education components 2017,Document number: Ningxia institutions of higher learning [2017] No.68.

\section{References}

[1] Sh. Zh. Wang and Ch. W. Hong, CDIO engineering education mode of classic, Institute of higher education research, 2009, vol. 4, pp. 116-119.

[2] L. Y. Sun and G. J. Yan,Based on college students' innovative experiment of cultivating the ability of CDIO project research, Journal of Shanxi university of finance and economics, 2010, vol. 2, pp. 76-79.

[3] J. T. Li, Probability and mathematical statistics, Beijing: higher education press, 2008,pp. 23-26.

[4] P. Z. Liang, Probability and mathematical statistics on the teaching mode of innovation, Higher education research journal, 2011, vol. 3, pp. 53-57.

[5] Y. T. Huang, The teaching experience of probability and statistics, information science and technology, 2010, vol. 5, pp. 15-18.

[6] S. T. Sun and Zh. X. Liang,Based on the concept of CDIO engineering teacher role transformation, Higher engineering education research, 2012, vol. 1, pp. 88-91. 